\title{
Observed progeny performance validates the benefit of mating genetically elite beef sires to dairy females
}

\author{
D. P. Berry ${ }^{1 *}$ (1) and S. C. Ring ${ }^{2}$ \\ ${ }^{1}$ Teagasc, Animal \& Grassland Research and Innovation Centre, Moorepark, Fermoy P61 P302, Co. Cork, Ireland \\ ${ }^{2}$ Irish Cattle Breeding Federation, Highfield House, Shinagh, Bandon P72 X050, Co. Cork, Ireland
}

\begin{abstract}
While several studies in cattle have confirmed the improved performance achievable from selection on total merit indexes, these studies have solely been confined to specific-purpose beef or dairy total merit indexes. Validation studies of total merit indexes used to select beef sires for use on dairy females are lacking. The objective here was to fill this void by quantifying the performance of beef $\times$ dairy progeny where the sire excels in either a total merit index encompassing calving performance and beef performance traits (dairy-beef index; DBI) or excels in a subindex based solely on calving performance (CLV); for comparative purposes, these beef $\times$ dairy progeny were also compared with dairy $\times$ dairy progeny. A total of 123,785 calving records from 101,773 dairy cows calving in 3,065 dairy herds were used; of these, 48,875 progeny also had carcass information. The beef sires were stratified into 5 equally sized groups based separately on their DBI or CLV. Linear and threshold mixed models were used to compare calving and carcass performance of all 3 sire genotypes. Of the 415 sires that ranked in the highest of the 5 strata on the CLV subindex, only $52 \%$ of them ranked in the highest stratum for the DBI. The percentage of primiparae requiring any assistance at calving was 2 to 3 percentage units greater for the higher DBI sires relative to both the higher CLV beef sires and the dairy sires (not ranked on anything); no difference existed in multiparae. The extent of calving difficulty in primiparae was, however, less in higher DBI beef sires relative to both the higher CLV beef sires and the dairy sires, although the differences were biologically small. Perinatal mortality was greatest in the beef sires relative to the dairy sires, but no difference existed between the high CLV or high DBI beef sires. No difference in progeny gestation length was evident
\end{abstract}

Received August 8, 2019.

Accepted November 18, 2019.

*Corresponding author: donagh.berry@teagasc.ie between the high DBI or high CLV beef sires, although both were $>2 \mathrm{~d}$ longer than progeny from dairy sires. The higher DBI sires produced progeny with heavier, more conformed carcasses relative to the progeny from both high CLV beef sires and dairy sires. No differences existed between the progeny of the beef sires ranked highly on the CLV versus those ranked highly on the DBI for the probability of achieving the specification for carcass weight (between 270 and $380 \mathrm{~kg}$ ) or fat score; the higher DBI animals, however, had a 4 to $10 \%$ greater probability of achieving the minimum carcass conformation required. In all instances, the beef sires had a greater probability of achieving all specifications relative to the progeny from the dairy sires with the difference for conformation being particularly large. Results indicate that more balanced progeny can be generated using a DBI, helping meet the requirements of both dairy and beef producers. Ignoring market failure across sectors, using higher DBI sires could increase dairy herd profit by 3 to $5 \%$ over and above the status quo approach to selection in dairy (i.e., CLV subindex). Key words: dairy beef, genetic, carcass, selection index, calving difficulty

\section{INTRODUCTION}

Validation of tools is paramount to widespread acceptance and, by extension, rapid adoption. From the perspective of animal breeding, the end user must be confident that differences in genetic merit translate to respective differences in phenotypic performance; this is true irrespective of whether these are based on individual traits or a breeding objective combining a series of traits. A plethora of studies based on analyses of national databases have proven that individuals excelling in genetic merit for an individual trait outperform their genetically inferior counterparts for that trait in both dairy cattle (Craig et al., 2018; Dunne et al., 2019b) and beef cattle (Crews, 2002; McHugh et al., 2014; Judge et al., 2019). Smaller scale experimental studies have also substantiated these conclusions in cattle (Campion et al., 2009). Less well publicized is the 
performance differential in animals divergent for overall breeding objectives. Using a database of 1,131 Irish dairy herds, Ramsbottom et al. (2012) illustrated how dairy herds with cows excelling in genetic merit for the Irish national dairy cow breeding objective were more profitable than herds of lower overall genetic merit. Newton et al. (2017) concluded the same following their analysis of 3 dairy herds in South Australia where cows were stratified, within contemporary group, as either high or low based on the Australian national breeding index; the higher index dairy cows were more profitable than their lower index contemporaries. Analyses of large databases of beef cattle have also revealed that beef animals divergent for an overall index outperform genetically inferior animals (Connolly et al., 2016). Smaller scale controlled experimental studies in both dairy cattle (Macdonald et al., 2008; Coleman et al., 2009; O'Sullivan et al., 2019) and beef cattle (Clarke et al., 2009a,b) divergent for overall breeding goals corroborate the findings from the larger data sets; animals genetically excelling for an overall breeding objective, on average, outperform their genetically inferior contemporaries.

All studies to date have compared the performance of animals differing in either a breeding objective for dairy animals or a breeding objective for beef animals, but no large study exists comparing progeny from dairy females bred to sires differing in genetic merit for a breeding objective designed specifically for dairy-beef production. Moreover, dairy farmers have traditionally selected bulls for mating, irrespective of breed, on just traits associated with calving performance credentials, namely calving dystocia and gestation length. The objective therefore of the present study was to use the data from the Irish national database to compare a series of performance metrics from the progeny of beef sires bred to dairy females. The beef sires differed genetically on the index proposed by Berry et al. (2019a) that ranks beef sires based on expected progeny profit when mated to dairy females. The performance of progeny from sires excelling on this index versus those from sires ranking highly on genetic merit for calving performance alone was also quantified. The estimated overall index value of the beef sires used in the analysis was derived before the mating, thus providing a real-life representation of what is expected to materialize from using such sires. The importance of such a validation study is particularly timely given the increasing use of beef bulls on dairy farmers. In the year 2018, $45 \%$ of Irish calves from Holstein-Friesian dams were sired by a beef bull (Department of Agriculture, Food and the Marine, 2019); this is a stark increase from $32 \% 5$ yr previous (Department of Agriculture, Food and the Marine, 2014).

\section{MATERIALS AND METHODS}

All cattle data used in the present study were sourced from the Irish Cattle Breeding Federation (http://www .icbf.com) national database. The dairy-beef index (DBI) used to rank the beef sires was that proposed by Berry et al. (2019a) as

$$
\mathrm{DBI}=\mathrm{CLV}+\mathrm{BF},
$$

where CLV represents the calving subindex of the DBI and $\mathrm{BF}$ represents the beef subindex of the DBI. The CLV and BF subindex were separately defined as

$$
\begin{gathered}
\text { CLV = calving difficulty }+ \text { mortality } \\
\quad+\text { gestation length }, \\
\mathrm{BF}=\text { docility }+\mathrm{DMI}+\text { carcass weight } \\
+ \text { carcass conformation }+ \text { carcass fat. }
\end{gathered}
$$

Each trait was a function of the economic weight, cumulative discounted genetic expressions, and sire PTA, all of which were defined by Berry et al. (2019a). Caving difficulty included a nonlinear economic effect (Berry et al., 2019a). When considering the 3 carcass traits, Berry et al. (2019a) also calculated the probability that the progeny of a given sire would achieve a minimum threshold imposed for carcass weight, conformation, and fat score; this was also included in the BF subindex.

The PTA used to populate the DBI for each sire were those from the national genetic evaluation in 2014 for each trait in the DBI. The data used to validate the index was only that from calves born from the year 2015 onward. All genetic evaluations are undertaken in a multi-breed framework with all dairy and beef animals (and crossbreds) in the same evaluation. Therefore, the PTA are directly comparable for all breeds including between dairy and beef breeds. The reliability for each PTA per animal was also available.

\section{Phenotypic Data}

Calving performance data were available on 2,556,216 calving events from 1,254,064 cows in 10,381 dairy herds, all recorded between the years 2015 and 2019. Calving performance traits here relate to calving difficulty score, perinatal calf mortality (i.e., dead within $24 \mathrm{~h}$ of birth), and gestation length. It is a legal requirement in Ireland to record all animal mortality events. The extent of calving assistance is measured subjectively by Irish farmers on a scale of 1 to 4 as (1) no assistance, (2) assistance provided with some calving difficulty, (3) 
assistance provided with considerable calving difficulty but without veterinary intervention, and (4) assistance provided with considerable calving difficulty resulting in veterinary intervention. Assistance in the present study was defined as either no assistance (i.e., score 1) versus some assistance (i.e., scores 2, 3, and 4); dystocia in the present study was defined as no assistance and some assistance combined (i.e., scores 1 and 2) versus considerable assistance or greater (i.e., scores 3 and 4). Herd-years were only retained if some variability in calving difficulty score was recorded. Subsequently, only calving events from a recorded sire and dam where the dam was a dairy breed were retained. The sire breed had to be one of the predominant beef breeds used in Ireland: Angus, Aubrac, Belgian Blue, Charolais, Limousin, Simmental, Hereford, Piedmontese, Parthenaise, Blonde d'Aquitaine, or Saler; for comparison purposes, calves sired by Holstein-Friesian sires were also retained. A total of 1,490,934 calving events from 834,637 dairy cows in 8,571 herds remained. A restriction was imposed that the reliability of the genetic evaluations for the traits of interest for all sires had to be $\geq 25 \%$ so that only sires with reasonable information, even if just a pedigree index, were considered. A total of $1,035,496$ calving events from 650,711 cows remained. Of these, 667,463 calving events had information on gestation length varying from 271 to $300 \mathrm{~d}$.

Carcass weight, conformation, and fat score information was available on 219,213 of the animals $(6,872$ herds) that also had information on calving performance from the edited data set. Only animals born in 2015 and 2016 were considered here so that all animals were born at least 30 mo before data extraction. Both carcass fat and conformation are scored on 15-point scales, in accordance with the EUROP grading system measured by a video-image-analysis machine (Pabiou et al., 2011). A conformation and fat score of 1 represents poor conformation and low fat cover, respectively, with a score of 15 representing the direct opposite (Englishby et al., 2016). Young bulls were slaughtered between 14 and 24 mo of age, heifers were slaughtered between 16 and 30 mo of age, and steers were slaughtered between 18 and 36 mo. Irish abattoirs impose a minimum carcass conformation score, and both upper and lower bounds for both carcass weight and carcass fat; carcasses are financially penalized if not within any of these thresholds. Three separate variables were therefore defined to denote whether the carcass achieved the predefined specifications or not. The desirable carcass weight is between 270 and $380 \mathrm{~kg}$ with the desirable carcass fat score (1 to 15 scale) being between 6 and 11; the minimum carcass conformation score (scale 1 to 15 ) is 5 with no upper threshold enforced. If the carcass achieved all 3 carcass specifications, then it was assumed to have achieved the overall specification, otherwise not.

Contemporary groups of herd-year-season of calving were defined for the calving performance traits in primiparous and multiparous cows separately. Contemporary group of year-by-season of slaughter was defined for each finishing herd by sex. Contemporary groups were all defined using an algorithm routinely used in Irish national genetic evaluations (Berry et al., 2013; Berry and Evans, 2014; McHugh et al., 2014). A maximum of $90 \mathrm{~d}$ duration was allowed for each contemporary group and each contemporary group had to have at least 5 records. The final edit imposed was that each contemporary group had to have at least 3 progeny from beef sires to be considered. The final data set for analysis included 123,785 calving records from 101,773 cows calving in 3,065 herds; of these, 48,875 animals had carcass information.

\section{Analysis}

The total number of beef sires with progeny in the data sets was 2,192; the number of Holstein-Friesian sires was 2,337 . The beef sires were stratified into 5 equally sized groups based on their DBI; for comparison purposes, the beef sires were separately divided into 5 groups based on their CLV subindex. In both situations, dairy sires were coded as a separate group.

Mixed models in ASReml (Gilmour et al., 2009) were used to quantify the relationship between each of the performance variables separately with either sire group (i.e., DBI, CLV, or dairy sire) after adjusting for nuisance factors in the statistical model. Linear models were used for the performance traits that were normally distributed (i.e., carcass weight, carcass conformation, carcass fat score, and gestation length). Threshold models assuming a logit link function while also accounting for the binomial error distribution were used when the dependent performance variable was binary; these traits included calving assistance, calving dystocia, perinatal mortality, and whether or not the carcass achieved the specification for carcass weight, the specification for carcass conformation, the specification for carcass fat, and finally the overall specification.

The statistical models used were

$$
\begin{aligned}
& \mathrm{Y}_{1}=\text { parity }+ \text { heterosis }+ \text { recombination }+\mathrm{PTA}_{\mathrm{DAM}} \\
& \quad+\text { sex } \times \text { age }+ \text { stratum }+ \text { sire }+\mathrm{CG}+\mathrm{e}, \\
& \mathrm{Y}_{2}=\text { parity }+ \text { heterosis }+ \text { recombination }+\mathrm{PTA}_{\mathrm{DAM}} \\
& +\mathrm{PTA}_{\mathrm{DAM} \_\mathrm{MAT}}+\text { sex }+ \text { stratum }+ \text { sire }+\mathrm{CG}+\mathrm{e},
\end{aligned}
$$




$$
\begin{gathered}
\mathrm{Y}_{3}=\text { parity }+ \text { heterosis }+ \text { recombination }+ \text { PTA }_{\mathrm{DAM}} \\
+ \text { sex }+ \text { stratum }+ \text { sire }+\mathrm{CG}+\mathrm{e},
\end{gathered}
$$

where $Y_{1}=$ the carcass traits; $Y_{2}=$ calving assistance, dystocia, or perinatal mortality; and $\mathrm{Y}_{3}=$ gestation length; parity $=$ dam parity $(1,2,3,4$, and $5+)$; heterosis $=$ covariate of heterosis coefficient of the animal (for carcass traits) or dam (for calving performance traits); recombination $=$ covariate of recombination loss coefficient of the animal (for carcass traits) or dam (for calving performance traits); $\mathrm{PTA}_{\mathrm{DAM}}=$ predicted transmitting ability of the dam for the direct effect of the trait under investigation; $\mathrm{PTA}_{\mathrm{DAM}_{\mathrm{MAT}}}=$ predicted transmitting ability of the dam for maternal genetic effect of the trait under investigation; sex $=$ sex of the animal (male and female in the case of all calving traits, but bulls, steers, or heifers in the case of the carcass traits); age $=$ class effect of age, in months, at slaughter; stratum = either DBI or CLV stratum (as well as a separate stratum for progeny from dairy sires); sire = sire of the calf; $\mathrm{CG}=$ contemporary group; and $\mathrm{e}=$ residual; parity was not included in the calving assistance or dystocia models when based just on primiparae. In all models, both sire and contemporary group were included as random effects. Predicted probability estimates and least squares means were generated from the models and are presented as the average of the population.

\section{RESULTS}

A $2 \times 2$ contingency table of the number of beef sires stratified by CLV subindex versus those stratified by DBI is shown in Table 1 . Of the 415 sires that ranked in the highest of the 5 strata on the CLV subindex, only $52 \%$ of them ranked highest on DBI; $32 \%$ of the sires ranked in the second highest stratum on DBI with a further $14 \%$ ranking average on the DBI stratum. Of the sires that ranked in the highest stratum on DBI, $53 \%$ ranked highest on CLV with a further $25 \%$ ranking average or worse on CLV.

\section{Carcass Traits}

The mean carcass weight, conformation, and fat score of progeny from sires stratified on CLV or on DBI are in Figure 1. The regression coefficient (SE) of carcass weight, conformation, and fat score on the respective trait PTA for the dam was 0.91 (0.03), 0.92 (0.02), and 1.05 (0.05), which are all very close to the expectation of unity. Mean carcass weight and conformation score was greatest in the progeny from lower DBI sires relative to high DBI sires. Mean carcass weight and conformation score also improved almost consistently as sire CLV subindex worsened. The mean carcass performance of progeny from the top $20 \%$ of beef sires ranked either on the CLV subindex or DBI, as well as all progeny born to dairy sires, is shown in Table 2.

Mean PTA for carcass weight, conformation, and fat score differed between each of the 3 categories of sires assessed (i.e., high CLV, high DBI, or dairy sires). When the carcass traits were assessed on a continuous basis, differences in mean phenotypic performance of the 3 categories of sires also existed. The difference in mean PTA for carcass weight, conformation and fat score between the high CLV and high DBI animals was largely reflected in their progeny performance. The carcass weight PTA of the higher DBI sires was $8.09 \mathrm{~kg}$ heavier than that of the higher CLV sires and this was reflected in a phenotypic difference of 8.58 $\mathrm{kg}$ in their progeny; the magnitude of differences in phenotypic performance relative to expectation based on the sire mean genetic merit was also very similar for conformation score (PTA difference $=0.26$; phenotypic difference $=0.24)$ and carcass fat $(\mathrm{PTA}$ differences $=$ -0.21 ; phenotypic difference $=-0.20$ ). Whereas the phenotypic progeny differences between the beef and dairy sires mirrored expectations based on genetic merit for carcass conformation and fat score, the expected phenotypic difference in progeny carcass weight between the beef and dairy sires was less than expected. In fact, no difference in progeny carcass weight existed between the beef sires ranked highly on the CLV subindex versus the dairy sires despite a respective difference

Table 1. Contingency table of the number of beef bulls, from a total of 2,192 bulls, within 5 strata on the calving subindex versus the 5 strata on the dairy-beef index

\begin{tabular}{lcrcrc}
\hline & \multicolumn{5}{c}{ Calving subindex } \\
\cline { 2 - 6 } Dairy-beef index & Very high & High & Average & Poor & Very poor \\
\hline Very high & 216 & 91 & 51 & 40 & 10 \\
High & 133 & 183 & 98 & 13 & 20 \\
Average & 59 & 136 & 192 & 21 & 37 \\
Poor & 7 & 21 & 114 & 204 & 91 \\
Very poor & 0 & 0 & 4 & 174 & 277 \\
\hline
\end{tabular}


of $6.02 \mathrm{~kg}$ in PTA. No differences existed between the progeny of the beef sires ranked highly on the CLV versus those ranked highly on the DBI for the probability of achieving the specification for carcass weight or fat score; progeny from the high DBI sires, however, had a 4 to $10 \%$ greater probability of achieving the carcass

(a)

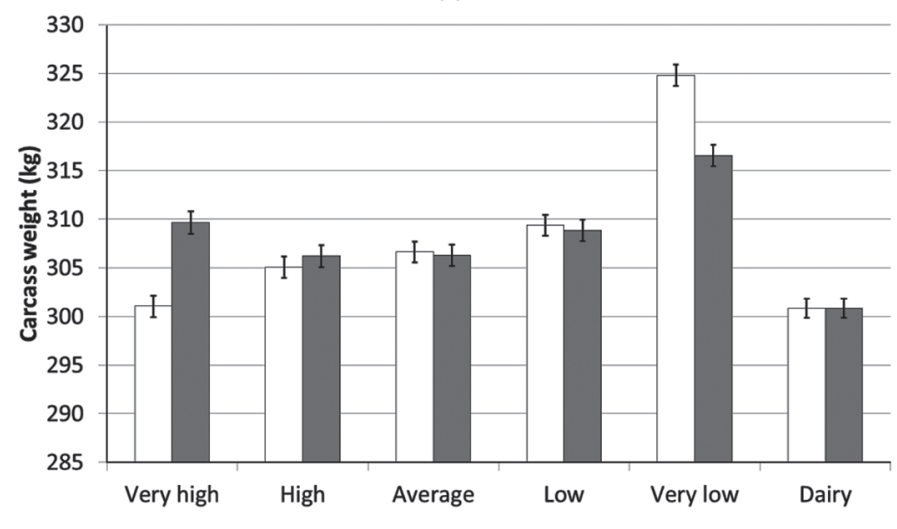

(b)

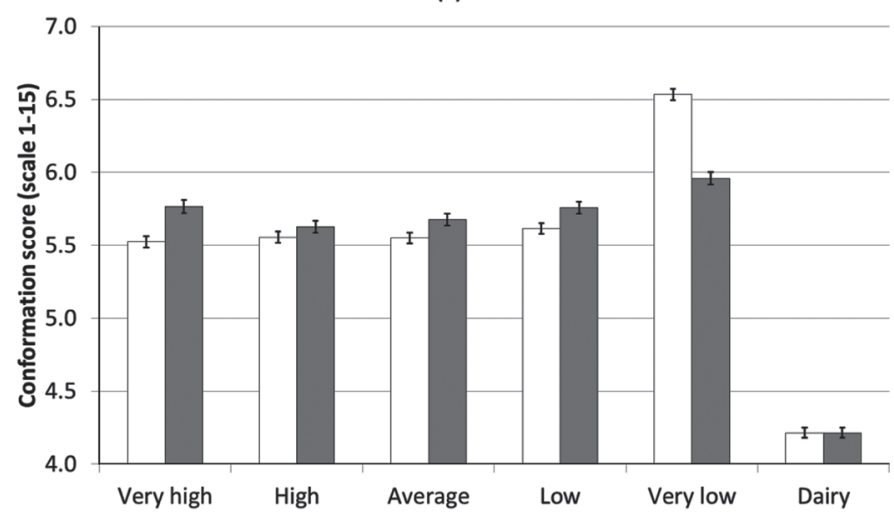

(c)

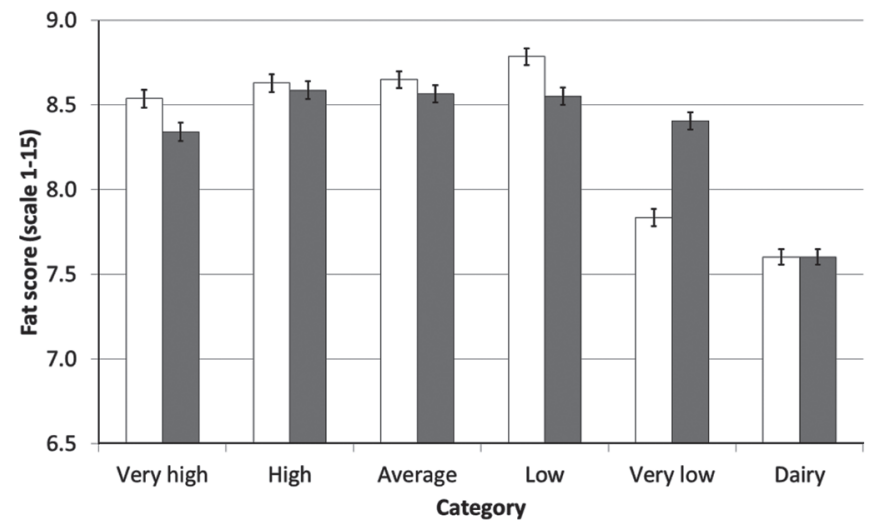

Figure 1. Least squares means for (a) carcass weight, (b) carcass conformation, and (c) carcass fat for progeny of beef bulls stratified on calving (unshaded bars) or dairy-beef index (shaded bars) as well as progeny from dairy bulls; error bars represent $1 \mathrm{SE}$ on each side of the LSM. conformation and overall specification relative to their high CLV counterparts. In all instances, the beef sires had a higher probability of achieving all carcass specifications relative to the progeny from the dairy sires with the difference for conformation being particularly large.

\section{Calving Performance Traits}

The mean genetic merit of the sires for all calvingrelated traits differed between the high CLV and high DBI beef sires as well as between both categories of beef sires and the dairy sires (Table 3). Relative to sires ranking in the top $20 \%$ on CLV, sires ranking in the top $20 \%$ on the DBI were genetically more predisposed to a difficult calving (i.e., calving score $\geq 3$ ) along with longer gestations and greater calf mortality. The same was true when comparing the high DBI beef sires to the dairy sires with the exception of calving difficulty in multiparous cows where the genetic merit for calving difficulty of the dairy sires was worse than that of the high DBI sires (and high CLV sires). Based on genetic merit for calving difficulty in primiparous cows, producers using the higher DBI sires were expected to experience just over 1 more dystocia event per 100 heifers calving compared with if they selected the higher CLV sires.

The phenotypic performance of progeny from high CLV beef sires, high DBI beef sires, and all dairy sires is shown in Table 3. The percentage of primiparae requiring assistance at calving (i.e., score $\geq 2$ on the 1 to 4 scale) was 2 to 3 percentage units greater for the higher DBI sires relative to both the higher CLV beef sires and the dairy sires; no difference was evident in multiparae. The extent of calving difficulty in primiparae was, however, less in higher DBI beef sires relative to both the higher CLV beef sires and dairy sires although the differences were biologically small; no difference was evident for calving dystocia in multiparous cows when comparing the higher DBI sires to either the higher CLV sires or the dairy sires. Perinatal mortality was highest in the beef sires relative to the dairy sires, but no difference existed between the high CLV or high DBI sires. No difference in progeny phenotypic gestation length was evident between the high DBI or high CLV beef sires, although both were $>2 \mathrm{~d}$ longer than progeny from dairy sires.

\section{DISCUSSION}

Selection indexes were originally proposed by Hazel (Hazel, 1943; reviewed by Hazel et al., 1994) as a means of achieving "maximum genetic progress towards a stated goal." The stated goal usually includes many (correlated) traits. Selection index approaches are par- 
Table 2. Mean (SE) sire PTA and progeny performance, defined on a continuous or binary scale (predicted probability values within 95\% CI), for beef bulls ranked in the top $20 \%$ for either the calving or dairy-beef index (DBI) in comparison with their dairy bull contemporaries ${ }^{1}$

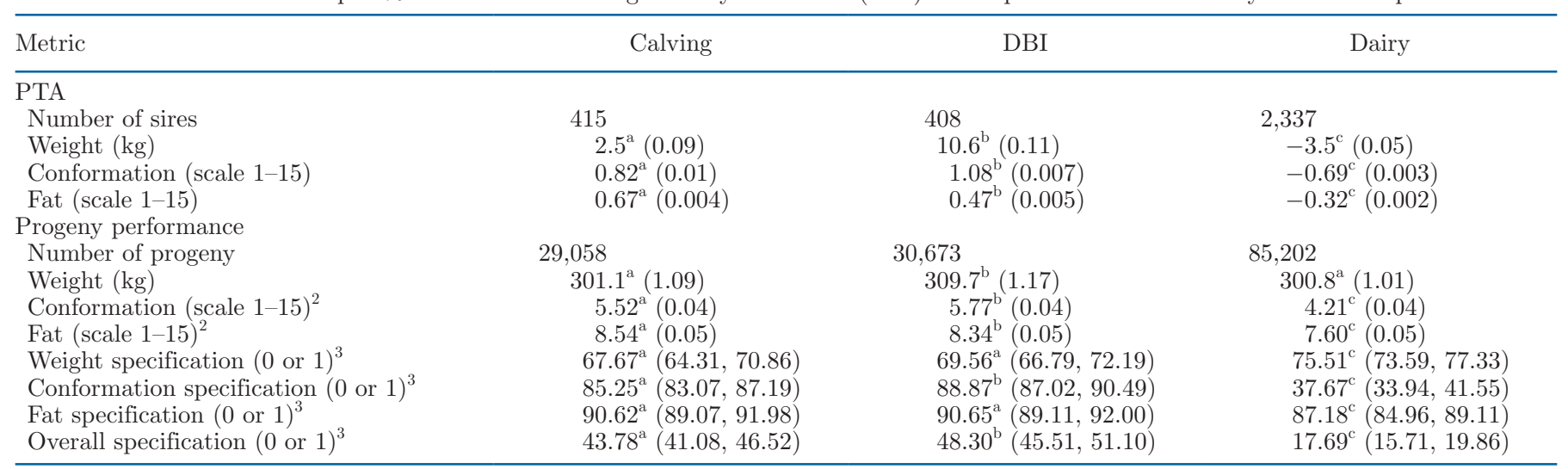

${ }^{\mathrm{a}-\mathrm{c}}$ Superscripts within a row that differ indicate significant $(P<0.05)$ differences.

${ }^{1}$ Also included is the number of sires and number of progeny for each category.

${ }^{2}$ Score of 1 represents poor conformation/lean carcass, and a score of 15 represents well-conformed/fat carcass.

${ }^{3} 0=$ specification was not achieved; 1 = specification was achieved.

ticularly beneficial over other selection approaches (i.e., independent culling levels or tandem selection) where antagonistic genetic correlations exist among the traits of interest (Hazel and Lush, 1942). Given the known antagonisms (Eriksson et al., 2004) that exist between calving performance (of interest to dairy producers) and carcass performance (of interest to beef producers), a selection index that combines both suites of traits is a logical strategy to try and improve both traits concurrently. Results from the present study support this.

The mean population parameters reported in the present study are generally similar to previous studies undertaken in Irish cattle using data that did not overlap with the data used herein. Using a population of 152,641 full-term dairy $\times$ dairy calving records from Irish Holstein-Friesian cows calving between the years 2002 and 2005, inclusive, Mee et al. (2011) reported an incidence of calving assistance of 40.0 and $28.2 \%$ in primiparae and multiparae, respectively, with a respective incidence of 9.3 and $5.8 \%$ for calving dystocia; both metrics are higher than reported in the present study. The calf perinatal incidence of $4.29 \%$ in Irish dairy cows reported by Mee et al. (2008) is also higher than the 1.67 to $2.27 \%$ estimated in the present study; the incidence reported in the present study is, however, more similar to the more recent estimate of $2.47 \%$ reported by Fitzgerald et al. (2015) from Irish dairy farms. The mean gestation length of $281 \mathrm{~d}$ in dairy sires and 283 to $284 \mathrm{~d}$ in beef sires in the present study is consistent with that reported previously for Irish dairy cattle (Fitzgerald et al., 2015); Fitzgerald et al. (2015) reported a mean gestation length of $280.8 \mathrm{~d}$ in HolsteinFriesians and a range of 283 to 284 in beef sires. Based on a controlled study of 170 male cattle from Irish dairy cows, Campion et al. (2009) reported a mean carcass weight of $316 \mathrm{~kg}$ (305.4 kg in the present study) and

Table 3. Mean (SE) sire PTA and progeny performance, defined on a continuous (gestation length) or binary scale (all other traits; predicted probability values within $95 \% \mathrm{CI}$ ), for beef bulls ranked in the top $20 \%$ for either the calving or dairy-beef index (DBI) in comparison with their dairy bull contemporaries

\begin{tabular}{|c|c|c|c|}
\hline Metric & Calving & DBI & Dairy \\
\hline \multicolumn{4}{|l|}{ PTA } \\
\hline Calving difficulty (\%; primiparous) & $6.70^{\mathrm{a}}(0.06)$ & $7.90^{\mathrm{b}}(0.07)$ & $6.14^{\mathrm{c}}(0.03)$ \\
\hline Calving difficulty (\%; multiparous) & $1.97^{\mathrm{a}}(0.03)$ & $2.76^{\mathrm{b}}(0.03)$ & $3.02^{\mathrm{c}}(0.01)$ \\
\hline Gestation length (d) & $-0.39^{\mathrm{a}}(0.02)$ & $-0.19^{\mathrm{b}}(0.02)$ & $-2.56^{\mathrm{c}}(0.01)$ \\
\hline \multicolumn{4}{|l|}{ Performance } \\
\hline Calving assistance ( 0 or 1 ; primiparous $)^{1}$ & $18.81^{\mathrm{a}}(15.89,21.73)$ & $21.77^{\mathrm{b}}(18.71,24.83)$ & $19.37^{\mathrm{a}}(17.57,21.17)$ \\
\hline Calving difficulty (0 or 1 ; multiparous $)^{1}$ & $0.81^{\mathrm{a}}(0.00,1.65)$ & $1.62^{\mathrm{ab}}(0.78,2.46)$ & $2.18^{\mathrm{b}}(1.73,2.63)$ \\
\hline Perinatal mortality (\%) & $2.27^{\mathrm{a}}(1.78,2.76)$ & $2.41^{\mathrm{a}}(1.92,2.90)$ & $1.67^{\mathrm{b}}(1.36,1.98)$ \\
\hline Gestation length (d) & $283.4^{\mathrm{a}}(0.38)$ & $283.8^{\mathrm{a}}(0.38)$ & $281.2^{\mathrm{b}}(0.29)$ \\
\hline
\end{tabular}

\footnotetext{
${ }^{\mathrm{a}-\mathrm{c}}$ Superscripts within a row that differ indicate significant $(P<0.05)$ differences.

${ }^{1} 0=$ no assistance/difficulty; $1=$ assistance/difficulty.
} 
$311 \mathrm{~kg}$ (300.8 kg in the present study) for beef $\times$ dairy and dairy $\times$ dairy animals; all beef $\times$ dairy animals in the study by Campion et al. (2009) were from either Angus or Belgian Blue sires. The mean conformation score (scale 1 to 15 ) of the 170 beef $\times$ dairy and dairy $\times$ dairy males was 6.88 (5.65 in the present study) and 4.5 (4.21 in the present study), respectively (Campion et al., 2009); the respective fat scores were 8.43 (8.44 in the present study) and 8.75 (7.6 in the present study).

\section{Beef Versus Dairy Sires}

The observed benefits in the present study of using beef sires, irrespective of whether selected using the CLV or DBI, over and above using dairy sires were superior carcass conformation and a greater proportion of progeny achieving the carcass conformation and overall carcass specifications; in the case of progeny from higher DBI sires, a benefit in carcass weight was also present. In a controlled study comparing Angus, Belgian Blue, Holstein, and Friesian-sired progeny from Irish dairy herds (Campion et al., 2009), differences in the carcass weight of the beef-sired progeny (which were stratified within breed on genetic merit) was not always evident; this is consistent with the results of the present study. Even in their analysis of slaughtered purebred beef and dairy young bulls from 15 different breeds, Alberti et al. (2008) failed to detect any difference in carcass weight between 30 Angus (i.e., the predominant beef breed used in the present study) bulls and 29 Holstein bulls; similar, however, to the present study, large differences in conformation score were evident between the 2 purebreds (Alberti et al., 2008).

Nonetheless, variability does exist within breeds (Figure 2; Berry et al., 2019b) and some dairy sires will produce progeny with superior carcass merit than the worst beef sires. The average superiority of beefsired animals over dairy-sired animals for carcass conformation is consistent with trends observed elsewhere (McGee et al., 2005; Campion et al., 2009; Berry et al., 2018). This observed improvement in carcass conformation (and in the case of progeny from high DBI sires, also carcass weight) is, however, as a consequence of a longer gestation, but depending on the choice of sire used (i.e., high on CLV or DBI), does not necessarily result in a greater incidence of calving assistance, dystocia, or perinatal mortality. Moreover, the variability among sires that exists within the beef breeds (Figure 2) points to the large scope that exists to identify sires that meet the specific requirements of individual producers.

Using the economic values for the DBI reported by Berry et al. (2019a) for carcass weight (€3.91), carcass conformation (€17.58), carcass fat score $(-€ 8.24)$ and achieving the carcass specification for conformation score (€56.52), the revenue accruing from a beef $\times$ dairy mating over a dairy $\times$ dairy mating is $€ 64.05$ based on just the carcass parameters that differed $(P<$ $0.05)$ from each other in the present study (i.e., carcass weight, conformation score, fat score, and achieving the conformation specification). Again using the economic values for the DBI reported by Berry et al. (2019a) for calving dystocia, perinatal mortality, and gestation length, the opportunity cost from a beef $\times$ dairy mating over a dairy $x$ dairy mating based on the significant parameters in the present study was €19.08. Hence, the overall expected profit considering just the carcass and calving performance traits of a beef $\times$ dairy cross over a dairy $\times$ dairy cross was $€ 44.97$ (i.e., $€ 64.05-€ 19.08$ ). However, not considered here is the social cost of using a beef sire on a dairy cow and the subsequent effect of avoiding the production of a calf that is often deemed to have a near zero monetary value (i.e., dairy bull calf). It is of course possible to generate beef calves that are worth considerably more relative to their purebred dairy counterparts (Figure 2). Nonetheless, given the genetic correlation between calving dystocia and carcass weight (Eriksson et al., 2004), such a selection policy will, on average, contribute to a greater cost via more calving-related issues and may not be financially sensible.

\section{Versus DBI}

The improved carcass performance of progeny from high DBI sires relative to those from high CLV sires is not unexpected given that the carcass traits considered in the present study form part of the DBI (but not CLV). The DBI selects from heavier carcasses of greater conformation and lower fat score. This was reflected in the phenotypic performance with the difference in phenotypic performance between progeny from high DBI and high CLV sires generally reflecting expectations based on the differentials in PTA. Nonetheless, the lack of large differences in mean phenotypic performance for the range of different traits evaluated between progeny from the highest DBI sires versus those from the highest CLV sires is also not unexpected given the strong part-whole relationship that exists between the DBI and the CLV subindex; the correlation between the CLV subindex and DBI of the Angus sires used in the present study was 0.71 signifying that many of the high DBI sires will also, on average, be high on CLV subindex. In fact, $53 \%$ of the highest DBI sires are the same sires that also rank highest on CLV (Table 1).

Using the economic values for the carcass traits from the DBI proposed by Berry et al. (2019a), the additional revenue from using a high DBI sire over a high 
(a)

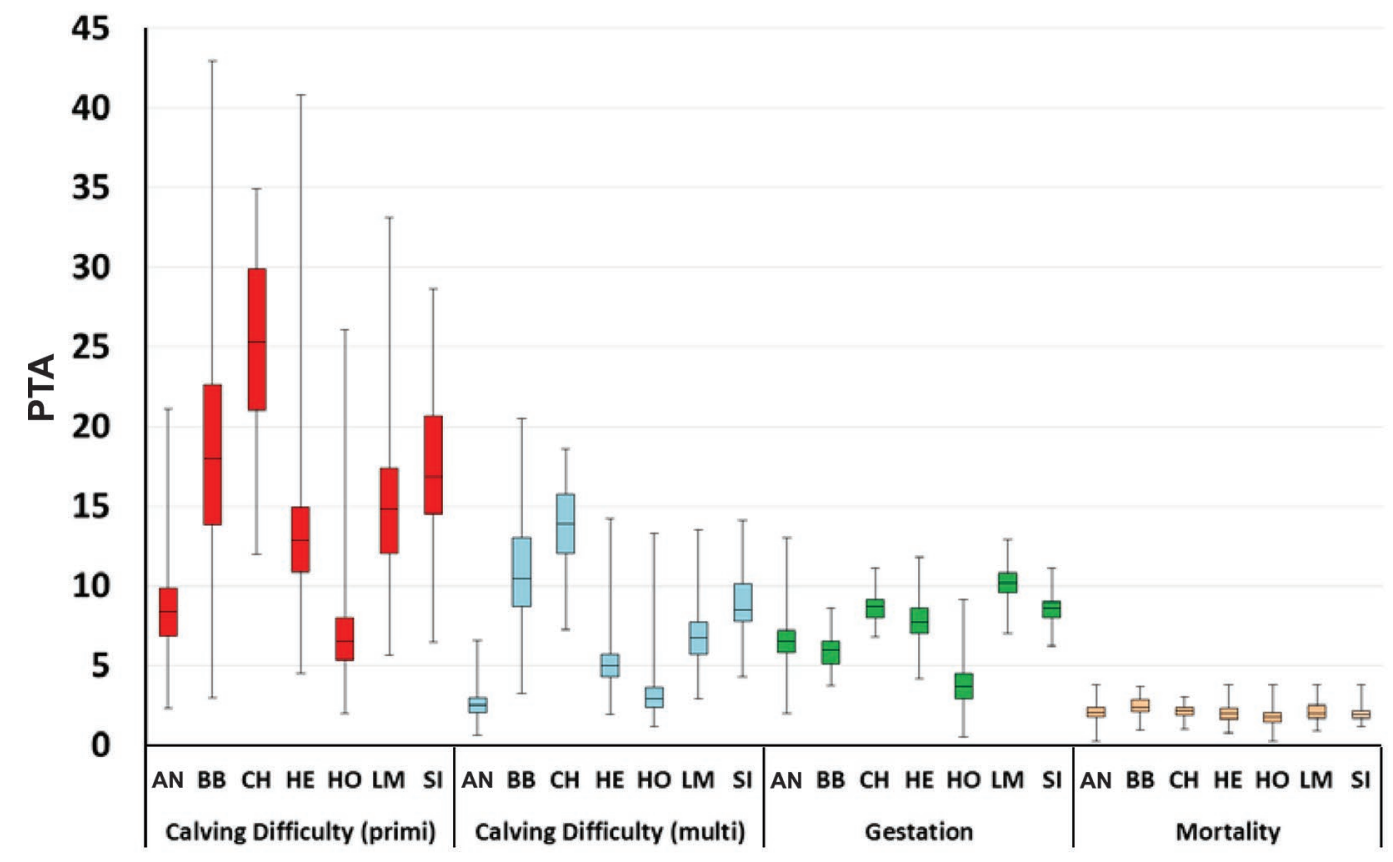

(b)

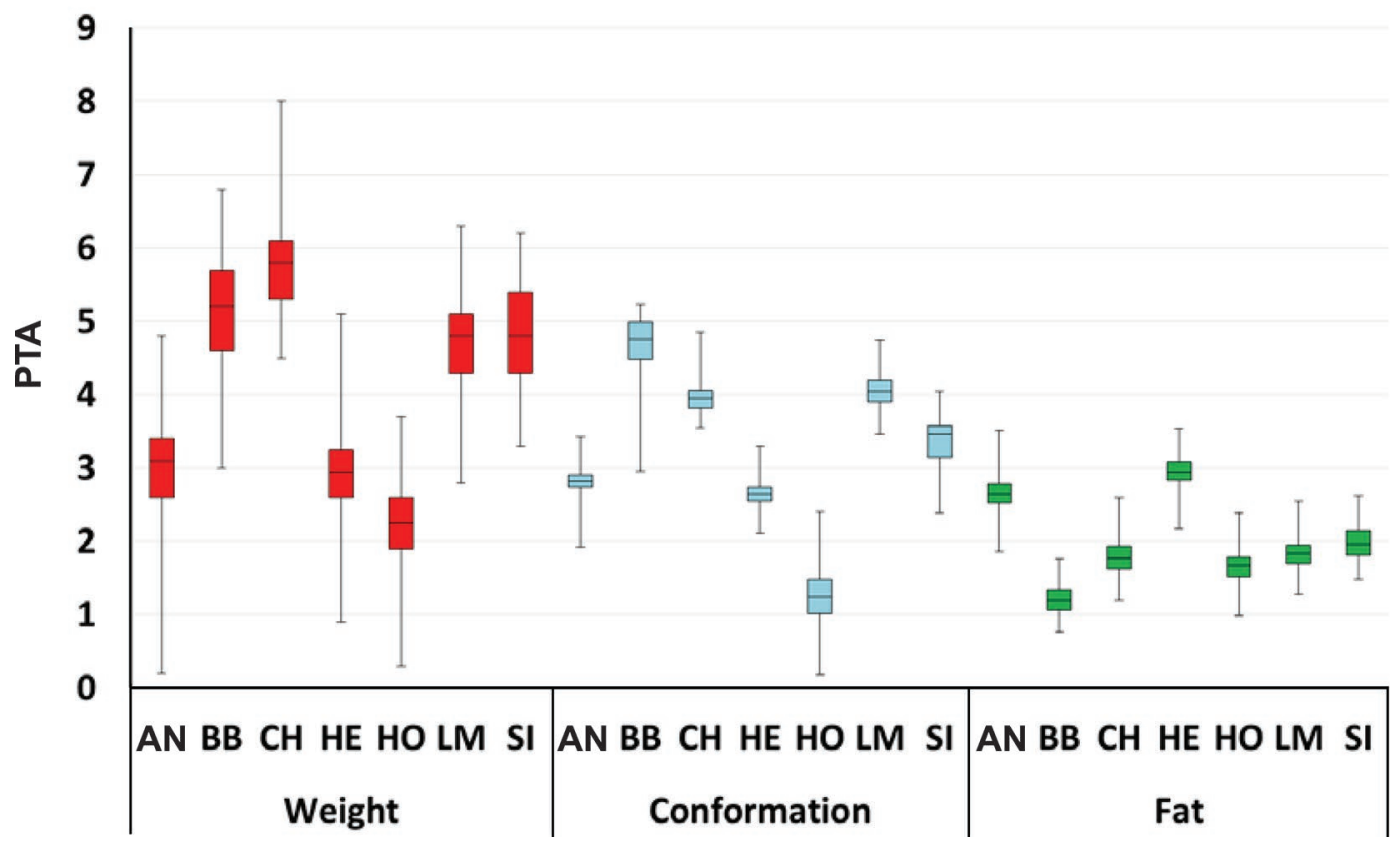

Figure 2. Box and whisker plot for PTA per breed. (a) Calving traits of calving performance in primiparous (primi) and multiparous (multi) cows (\% difficult), gestation length (d), and calf mortality (\%); and (b) carcass weight $(\mathrm{kg} \div 10)$, carcass conformation score (scale 1 to 15 ; poor to good), and carcass fat score (scale 1 to 15; lean to fat). AN = Angus; $\mathrm{BB}=$ Belgian Blue; $\mathrm{CH}=\mathrm{Charolais;} \mathrm{HE} \mathrm{=} \mathrm{Hereford;} \mathrm{HO} \mathrm{=} \mathrm{Holstein;}$ $\mathrm{LM}=$ Limousin; SI = Simmental. The horizontal line represents the median; $50 \%$ of the sires within breed lie within the range of the vertical box, with the remaining $50 \%$ located between the top or bottom of the box and the end of the whisker.

CLV sires considering just the carcass traits that differed $(P<0.05)$ from each other, was $€ 41.47$. For calving performance, the monetary benefit from using high
DBI sires compared with high CLV sires was €3.98. Therefore, the overall greater profit expected from using high DBI sires was $€ 45.45$; this is very similar to 
the expected benefit of using beef sires over using dairy sires $(€ 44.97)$ based on the results from the present study. Moreover, other tangible benefits from selection on DBI such as expected lower feed intake were not included in this calculation. The mean PTA for feed intake of the high DBI sires was $0.03 \mathrm{~kg}$ of DM/d less than the mean PTA for feed intake of the high CLV sires; this is not unexpected given the inclusion of feed intake in the DBI, despite the progeny from high DBI animals generating heavier carcasses. Assuming the differential in sire PTA materializes in differences in progeny phenotypic DMI (Dunne et al., 2019a), then the differences over a 120-d finishing period equate to the progeny from high CLV sires eating, on average, 3.6 $\mathrm{kg}$ of DM more than the progeny from high DBI sires. Assuming a cost of feed of $€ 300$ per tonne of DM, this adds a further $€ 1.08$ benefit to the high DBI sires over the high CLV sires.

The average family farm income (excluding direct payments) on Irish dairy farms for the years 2015 and 2016 (i.e., the years the animals with carcass data were born) was $€ 32,420$ and $€ 66,741$, respectively (National Farm Survey, 2017); the respective dairy cow herd size was 72 and 75 cows. Assuming $50 \%$ of the cows produce a live beef calf for sale, the additional carcass value alone of $€ 45.45$ from using high DBI versus high CLV sires equates to additional revenue (ignoring market failure) of $€ 1,635.84$ and $€ 1,704.00$, respectively. This represents 3 to $5 \%$ of the mean family farm income; the cost of rearing the calf should be the same irrespective of whether the calf is from a high DBI or high CLV sire. This value does, however, rely on the dairy farmer being fully rewarded for the value-added calf. Nonetheless, many Irish dairy farmers still rear their beef calves for harvest and would thus reap the rewards (as well as the cost savings in feed intake). Generation of a transaction index for calf predicted carcass value (Dunne et al., 2019a) would improve the transparency of the genetic merit of the calves being sold and, in doing so, promote a greater use of high DBI sires via a greater reward in the marketplace. Exploitation of sexed semen could further increase the percentage of family farm income attainable from generating higher value calves.

\section{Breeding Programs}

Because the difference in phenotypic performance between the high CLV and high DBI sires largely reflected their respective differences in PTA, breeding programs that improve genetic merit for one or more of the traits should lead to an associated improvement in phenotypic performance. Close corroboration between phenotypic performance differences relative to the expectation based on genetic merit has been documented previously in dairy (O'Sullivan et al., 2019) and beef (Connolly et al., 2016; Judge et al., 2019). One of the shortcomings of a selection index is that it is a linear function of its component traits; given this, it is possible for a sire excelling in genetic merit for $\mathrm{BF}$, but poor for CLV, to rank higher on an overall DBI compared with a more balanced sire for both indexes. This is clearly illustrated in Figure 3, which demonstrates the relationship, just within the sires of the Angus breed represented in the present study, between the CLV and $\mathrm{BF}$ subindexes of the DBI; a correlation of -0.17 exists between the CLV and BF subindex in the Angus sires in Figure 3. Of note is that that the construction of the DBI is attempting to shift the population to easy calving with superior beef performance (i.e., the top right of Figure 3). However, large diversity, even with the one breed, exists among sires in the top $20 \%$ on DBI. For example, of 2 extreme Angus sires in the top $20 \%$ on DBI, one had a CLV and BF value of $€ 58$ and -€12, respectively, while the other had a CLV and $\mathrm{BF}$ value of $€ 0.20$ and $€ 52$; the DBI of both sires is obviously similar ( $€ 46$ and $€ 52.20$ ), yet they would generate very different progeny and their recommended use on dairy females of given characteristics would differ. Moreover, although Angus is the predominant beef breed used in dairy females (Berry et al., 2019b), the large diversity that exists within individual breeds (Figure 2) implies that individual sires of most breeds are suited for mating to dairy females; it is the role of a breeding program to identify these sires. The evidence from successful dairy breeding programs on tandem selection for antagonistically correlated traits is clear. From a review of the literature on genetic parameters for dairy cow fertility, Berry et al. (2014) reported an antagonistic genetic correlation of 0.46 to 0.50 between milk production (analogous to $\mathrm{BF}$ here as the main output trait) and calving interval (analogous to CLV here as the main cost of production trait); despite this genetic correlation, which is considerably stronger than the absolute correlation of 0.17 between CLV and BF estimated in the present study, simultaneous favorable genetic trends in both traits are being achieved (Berry et al., 2014).

While national breeding programs, or breeding programs operated by individual breeding companies, generally focus on a single end-user group, within-herd breeding programs can be more bespoke and tailored to the females on the farm. For example, optimum sire selection for a herd with larger (older) cows, with a great propensity to calve bigger calves, is likely to differ from sires selected for smaller (young) cows (Berry et al., $2019 \mathrm{~b}$ ); the former sire selection strategy may compromise on genetic merit for calving difficulty in the pursuit of a more valuable calf. The within-herd breeding 


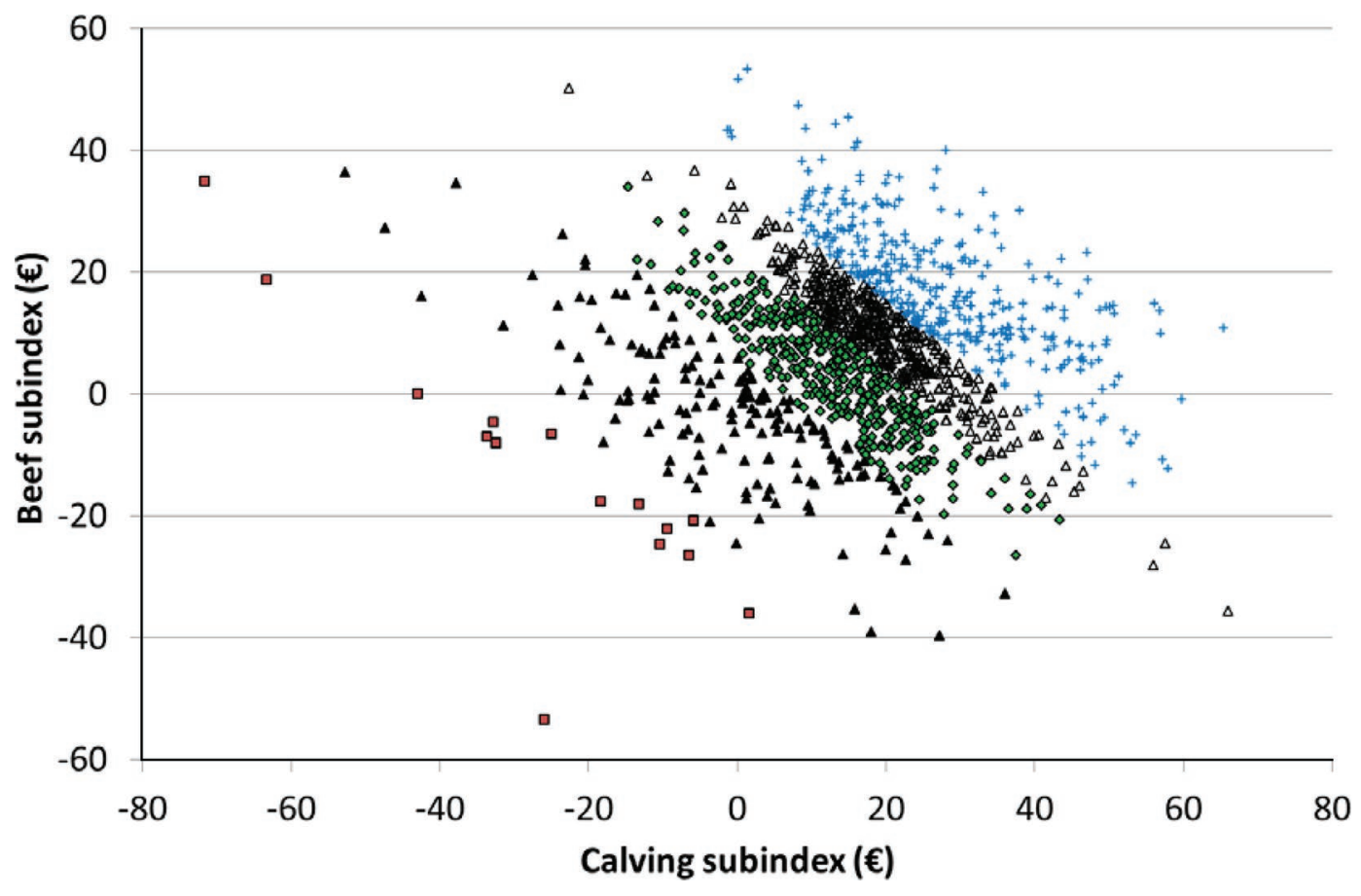

Figure 3. Scatter plot of the beef and calving subindex components of Angus bulls stratified into 5 groups based on the dairy-beef index. $=$ very low; $\boldsymbol{\Delta}=$ low; $\diamond=$ average; $\Delta=$ high; and $+=$ very high.

policy may also change over a breeding season. Genetically elite females in estrus early in a breeding season may be inseminated with high genetic merit dairy sires with inferior females in estrus early in the breeding season inseminated with beef sires. As the breeding season progresses and producers attempt to maximize their chances that the female will calve without complication early in the subsequent calving season, a decision may be made to increase the emphasis within the DBI on both easy calving and short gestation. Irrespective of the within-herd breeding policy, the sires available should be such that easy calving does not have to imply poorer quality calves.

\section{CONCLUSIONS}

The DBI is composed of traits relating to calving performance (of interest to the dairy producer) and those related to beef performance (of interest to the beef producer). The aim of the DBI is to rank sires on estimated genetic potential to efficiently produce a high-value carcass, while having minimal repercussions on the milk, health, and reproductive performance of the dairy female. Validation results from the present study demonstrate that the objective was achieved although clear room for improvement was evident. This will provide confidence to both dairy and beef breeders and producers that promoting and using this index will, on average, produce more valuable beef calves; this will be achieved with a minimal greater effect on the female over and above the current approach to selecting beef sires. The end result is greater profit.

\section{ACKNOWLEDGMENTS}

This publication has emanated from research supported by a research grant from Science Foundation Ireland and the Department of Agriculture, Food and Marine on behalf of the Government of Ireland under the Grant 16/RC/3835 (VistaMilk) as well as the Research Stimulus Fund Dairy4Beef. The authors have not stated any conflicts of interest.

\section{REFERENCES}

Alberti, P., B. Panea, C. Sañudo, J. L. Olleta, G. Ripoll, P. Ertbjerg, M. Christensen, S. Gigli, S. Failla, S. Concetti, J. F. Hocquette, R. Jailler, S. Rudel, G. Renand, G. R. Nute, R. I. Richardson, and J. L. Williams. 2008. Live weight, body size and carcass characteristics of young bulls of fifteen European breeds. Livest. Sci. 114:19-30. https://doi.org/10.1016/j.livsci.2007.04.010.

Berry, D. P., P. R. Amer, R. D. Evans, T. Byrne, A. R. Cromie, and F. Hely. 2019a. A breeding index to rank beef bulls for use on dairy females to maximise profit. J. Dairy Sci. 102:10056-10072. https:/ /doi.org/10.3168/jds.2019-16912.

Berry, D. P., and R. D. Evans. 2014. Genetics of reproductive performance in seasonal calving beef cows and its association with performance traits. J. Anim. Sci. 92:1412-1422. https://doi.org/ $10.2527 /$ jas.2013-6723. 
Berry, D. P., M. J. Judge, R. D. Evans, F. Buckley, and A. R. Cromie. 2018. Carcass characteristics of cattle differing in Jersey proportion. J. Dairy Sci. 101:11052-11060. https://doi.org/10.3168/jds .2018-14992.

Berry, D. P., J. F. Kearney, K. Twomey, and R. D. Evans. 2013. Genetics of reproductive performance in seasonal calving dairy cattle production systems. Ir. J. Agric. Food Res. 52:1-16.

Berry, D. P., S. C. Ring, A. J. Twomey, and R. D. Evans. 2019b. Choice of artificial insemination beef bulls used to mate with female dairy cattle. J. Dairy Sci. https://doi.org/10.3168/jds.2019 -17430 . In press.

Berry, D. P., E. Wall, and J. E. Pryce. 2014. Genetics and genomic of reproductive performances in dairy and beef cattle. Animal 8(s1):105-121. https://doi.org/10.1017/S1751731114000743.

Campion, B., M. G. Keane, D. A. Kenny, and D. P. Berry. 2009. Evaluation of estimated genetic merit for carcass weight in beef cattle: Live weights, feed intake, body measurements, skeletal and muscular scores, and carcass characteristics. Livest. Sci. 126:87-99. https://doi.org/10.1016/j.livsci.2009.06.004.

Clarke, A. M., M. J. Drennan, M. McGee, D. A. Kenny, R. D. Evans, and D. P. Berry. 2009a. Intake, growth and carcass traits in male progeny of sires differing in genetic merit for beef production. Animal 3:791-801. https://doi.org/10.1017/S1751731109004200.

Clarke, A. M., M. J. Drennan, M. McGee, D. A. Kenny, R. D. Evans, and D. P. Berry. 2009b. Live animal measurements, carcass composition and plasma hormone and metabolic concentrations in male progeny of sires differing in genetic merit for beef production. Animal 3:933-945. https://doi.org/10.1017/S1751731109004327.

Coleman, J., K. M. Pierce, D. P. Berry, A. Brennan, and B. Horan. 2009. The influence of genetic selection and feed system on the reproductive performance of spring-calving dairy cows within future pasture-based production systems. J. Dairy Sci. 92:5258-5269. https://doi.org/10.3168/jds.2009-2108.

Connolly, S. M., A. R. Cromie, and D. P. Berry. 2016. Genetic differences based on a beef terminal index are reflected in future phenotypic performance differences in commercial beef cattle. Animal 10:736-745. https://doi.org/10.1017/S1751731115002827.

Craig, H. J. B., K. Stachowicz, M. Black, M. Parry, C. Burke, S. Meier, and P. Amer. 2018. Genotype by environment interactions in fertility traits in New Zealand dairy cows. J. Dairy Sci. 101:1099111003. https://doi.org/10.3168/jds.2017-14195.

Crews, D. H. Jr. 2002. The relationship between beef sire carcass EPD and progeny phenotype. Can. J. Anim. Sci. 82:503-506. https:// doi.org/10.4141/A02-037.

Department of Agriculture, Food and the Marine. 2014. AIM Bovine Statistics Report. Accessed Oct. 22, 2019. https://www.agriculture.gov.ie/media/migration/animal healthwelfare/animalidentificationandmovement/cattlemovement monitoringsystem/AIMBOVINESTATISTICS2013050614.pdf.

Department of Agriculture, Food and the Marine. 2019. AIM Bovine Statistics Report. Accessed Oct. 22, 2019. https://www.agriculture .gov.ie/media/migration/animalhealthwelfare/animal identificationandmovement/ AIMBovineStatisticsReport 2018100519.pdf.

Dunne, F. L., R. D. Evans, M. M. Kelleher, S. W. Walsh, and D. P. Berry. 2019a. Formulation of a decision support tool incorporating both genetic and non-genetic effects to rank young growing cattle on expected market value. J. Anim. Sci. In press.

Dunne, F. L., S. McParland, M. M. Kelleher, S. W. Walsh, and D. P. Berry. 2019b. How herd best linear unbiased estimates affect the progress achievable from gains in additive and nonadditive genetic merit. J. Dairy Sci. 102:5295-5304. https://doi.org/10.3168/jds .2018-16119.

Englishby, T. M., G. Banos, K. L. Moore, M. P. Coffey, R. D. Evans, and D. P. Berry. 2016. Genetic analysis of carcass traits in beef cattle using random regression models. J. Anim. Sci. 94:1354-1364. https://doi.org/10.2527/jas.2015-0246.

Eriksson, S., A. Nasholm, K. Johansson, and J. Philipsson. 2004. Genetic relationships between calving and carcass traits for Charolais and Hereford cattle in Sweden. J. Anim. Sci. 82:2269-2276. https: //doi.org/10.2527/2004.8282269x.

Fitzgerald, A. M., D. P. Ryan, and D. P. Berry. 2015. Factors associated with differential in actual gestational age and gestational age predicted from transrectal ultrasonography in pregnant dairy cows. Theriogenology 84:358-364. https://doi.org/10.1016/j .theriogenology.2015.03.023.

Gilmour, A. R., B. Gogel, B. Cullis, R. Thompson, and D. Butler. 2009. ASReml user guide release 3.0. VSN Int. Ltd., Hemel Hempstead, UK.

Hazel, L. N. 1943. The genetic basis for constructing selection indexes. Genetics 28:476.

Hazel, L. N., G. E. Dickerson, and A. E. Freeman. 1994. The selection index - Then, now, and for the future. J. Dairy Sci. 77:3236-3251. https://doi.org/10.3168/jds.S0022-0302(94)77265-9.

Hazel, L. N., and J. L. Lush. 1942. The efficiency of three methods of selection. J. Hered. 33:393-399. https://doi.org/10.1093/ oxfordjournals.jhered.a105102.

Judge, M. M., T. Pabiou, J. Murphy, S. Conroy, P. J. Hegarty, and D. P. Berry. 2019. Potential exists to change, through breeding, the yield of individual primal carcass cuts in cattle without increasing overall carcass weight. J. Anim. Sci. 97:2769-2779. https://doi .org/10.1093/jas/skz152.

Macdonald, K. A., G. A. Verkerk, B. S. Thorrold, J. E. Pryce, J. W. Penno, L. R. McNaughton, L. J. Burton, J. A. S. Lancaster, J. H. Williamson, and C. W. Holmes. 2008. A comparison of three strains of Holstein-Friesian grazed on pasture and managed under different feed allowances. J. Dairy Sci. 91:1693-1707. https://doi .org/10.3168/jds.2007-0441.

McGee, M., M. G. Keane, R. Neilan, A. P. Moloney, and P. J. Caffrey. 2005. Production and carcass traits of high dairy genetic merit Holstein, standard daily genetic merit Friesian and Charolais, Holstein-Friesian male cattle. Ir. J. Agric. Food Res. 44:215-231.

McHugh, N., A. R. Cromie, R. D. Evans, and D. P. Berry. 2014. Validation of national genetic evaluations for maternal beef cattle traits using Irish field data. J. Anim. Sci. 92:1423-1432. https:// doi.org/10.2527/jas.2013-6658.

Mee, J. F., D. P. Berry, and A. R. Cromie. 2008. Prevalence of, and risk factors associated with, perinatal calf mortality in pasturebased Holstein-Friesian cows. Animal 2:613-620.

Mee, J. F., D. P. Berry, and A. R. Cromie. 2011. Risk factors for calving assistance and dystocia in pasture-based Holstein-Friesian heifers and cows in Ireland. Vet. J. 187:189-194. https://doi.org/ 10.1016/j.tvjl.2009.11.018.

National Farm Survey (NFS). 2017. Teagasc, Dublin, Ireland.

Newton, J. E., M. E. Goddard, H. N. Phuong, M. A. Axford, C. K. M. Ho, N. C. Nelson, C. F. Waterman, B. J. Hayes, and J. E. Pryce. 2017. High genetic merit dairy cows contribute more to farm profit: Case studies of 3 Australian dairy herds. Proc. Anim. Breed. Genet 22:19-22.

O'Sullivan, M., B. Horan, K. M. Pierce, S. McParland, K. O'Sullivan, and F. Buckley. 2019. Milk production of Holstein-Friesian cows of divergent Economic Breeding Index evaluated under seasonal pasture-based management. J. Dairy Sci. 102:2560-2577. https:// doi.org/10.3168/jds.2018-15559.

Pabiou, T., W. F. Fikse, A. R. Cromie, M. G. Keane, A. Nasholm, and D. P. Berry. 2011. Use of digital images to predict carcass cut yields in cattle. Livest. Sci. 137:130-140. https://doi.org/10.1016/ j.livsci.2010.10.012.

Ramsbottom, G., A. R. Cromie, B. Horan, and D. P. Berry. 2012. Relationship between dairy cow genetic merit and profit on commercial spring calving dairy farms. Animal 6:1031-1039. https:// doi.org/10.1017/S1751731111002503.

\section{ORCIDS}

D. P. Berry @ https://orcid.org/0000-0003-4349-1447 